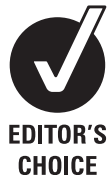

CHOICE
${ }^{1}$ Harvard School of Public Health, Center for Global Tobacco Control, Boston, Massachusetts, USA ${ }^{2}$ Research Institute for a Tobacco Free Society, Republic of Ireland

\section{Correspondence to}

Hillel R Alpert, Harvard School of Public Health, Center for Global Tobacco Control, Landmark Building, Floor 3E 401 Park Drive, Boston, MA 02215, USA; halpert@hsph.harvard.edu

Received 2 July 2010 Accepted 27 October 2010 Published Online First 26 January 2011

\title{
Smoke-free households with children and decreasing rates of paediatric clinical encounters for otitis media in the United States
}

\author{
Hillel R Alpert, ${ }^{1}$ Ilan Behm, ${ }^{1}$ Gregory N Connolly, ${ }^{1}$ Zubair Kabir ${ }^{2}$
}

\begin{abstract}
Objective Temporal trends in paediatric encounters for otitis media (OM) were last characterised and observed to be steadily increasing from 1975 to the mid-1990s.

The present study uses an ecological design to quantify trends in paediatric encounters for OM concurrent with a period of decline of an important risk factor, secondhand smoke (SHS) exposure among children.
\end{abstract}

Patients and methods Annual paediatric ambulatory visit and hospital discharge rates for children $\leq 6$ years with $\mathrm{OM}$ as primary diagnosis were computed with nationally representative data for 1993-2006.

Percentages of households with children $\leq 6$ years and no-smoking rules were computed using Tobacco Use Supplement to the Current Population Survey data. Average annual percentage changes were determined for covariate-adjusted rates of paediatric encounters for OM using joinpoint analysis.

Results While percentages of homes with children and no-smoking rules increased by $89 \%$ from $45.5 \%$ in 1993 to $86.1 \%$ in 2006 , average annual covariate-adjusted paediatric encounters for OM decreased by $4.6 \% 195 \%$ Cl $4.5 \%$ to $4.8 \%$ ) for ambulatory visits and by $9.8 \%$ (95\% Cl $9.1 \%$ to $10.6 \%$ ) for hospital discharges. Coverage by 7-valent pneumococcal conjugate vaccination (PCV7) increased since 2002, while little variation occurred in other potentially associated risk factors.

Conclusions Paediatric encounter rates for OM decreased steadily over a 13-year period reversing a previously reported long-term increasing trend reported. Reduced SHS exposure, PCV7 coverage since 2002 and other factors may have contributed to the decline. Further research is needed to provide direct estimates of paediatric encounter rates in exposed and unexposed populations for causal inference.

\section{INTRODUCTION}

Otitis media (OM) is the most common paediatric diagnosis made in physician office practices ${ }^{12}$ and the leading cause of medical encounters among children and preschool-aged children in the USA. ${ }^{23}$ The economic burden in terms of annual costs was estimated in the 1990 s to be $\$ 3$ billion to $\$ 5$ billion. $^{4-7}$ Dramatic increases were reported in the number of clinical visits for OM from 9.9 million in 1975 to 24.5 million in 1990, accounted for primarily by visits of children less than 15 years of age. ${ }^{4}$ Increases in paediatric physician office visits for $O M$ and the prevalence of early onset and recurrent $\mathrm{OM}$ among preschool children through 1994 were also reported, without concurrent increases in selected risk factors, childcare use, asthma, breastfeeding duration, allergic conditions and access to care. ${ }^{8}$

The possible role of exposure to secondhand tobacco smoke (SHS) in observed trends of OM encounters among children was not previously considered, prior to the increasing awareness of the health consequences of SHS since the mid-1990s. ${ }^{9} 10$ SHS, the combination of sidestream smoke released from a burning cigarette and mainstream smoke exhaled by an active smoker, ${ }^{11}{ }^{12}$ is known to raise indoor air levels of respirable particles as well as nicotine, polycyclic aromatic hydrocarbons, carbon monoxide and other toxic substances. ${ }^{11-13}$ The US Surgeon General reported in 2006 that sufficient evidence exists to infer a causal relation between parental smoking and $\mathrm{OM}$ in children. ${ }^{11} \mathrm{~A}$ recent meta-analysis concluded an increased risk of $\mathrm{OM}$ by an OR of 1.35 for household smoking, 1.46 for postnatal maternal smoking and 1.27 for paternal smoking. ${ }^{14}$ Exposure of children to SHS is of particular concern because it occurs involuntarily and predominantly in the home, where young children spend most of their time. ${ }^{11} 15$

Recent literature suggests that fewer children than previously may be exposed to SHS with a proliferation of smoke-free rules in households, approximately doubling since the mid-1990s, most probably because of evolving knowledge and attitudes regarding the adverse health effects of SHS and possibly the decline in overall smoking prevalence. ${ }^{11}{ }^{16-20}$ Prospective improvements in child health resulting from increases in smoke-free rules among homes with children have yet to be assessed. Of particular interest is whether the trend in the frequency of OM clinical encounters among children has decreased concurrently with expected home indoor air quality improvement since the mid-1990s. In order to examine this hypothesis, the possible influence following introduction of 7 -valent pneumococcal conjugate vaccination (PCV7) in 2000, which was shown in pre-licensure clinical trials to provide a small reduction in OM episodes and related office visits, ${ }^{21} 22$ needs also to be considered.

The purpose of the present study is to characterise trends in paediatric encounters for $\mathrm{OM}$ in the USA over a 13-year period from 1993 to 2006. Paediatric encounters across healthcare settings, including ambulatory care visits and hospital discharges, with $\mathrm{OM}$ as the primary diagnosis, are quantified using nationally representative data. This is an ecological analysis investigating temporal trends in paediatric encounters for $\mathrm{OM}$ concurrent 
with the proliferation of smoke-free rules in households and introduction of PCV7.

\section{PATIENTS AND METHODS}

The time-frame selected for this study begins in 1993, at the crest of an observed long-term increase in paediatric encounters for $\mathrm{OM}$ and at the outset of a trend towards increasing smoke-free households. The study period continues through 2006, the most recent year for which both household smoke-free rules and nationally representative paediatric encounter data were available.

\section{Percentages of smoke-free households with children}

Percentages of smoke-free households among homes with children aged 6 years or less were derived from the Tobacco Use Supplement to the Current Population Survey (TUS-CPS), a National Cancer Institute (NCI)-sponsored monthly survey of civilian, non-institutionalised household units in the USA. Data were analysed from all survey waves conducted including the years 1992-1993, 1995-1996, 1998-1999, 2001-2002, 2003 and $2006-2007,{ }^{23-28}$ and linear interpolation was used for estimates for the intervening years, 1994, 1997, 2000, 2004 and 2005.

The percentages of households with at least one child aged 6 years or less with a rule allowing no smoking anywhere in the home were calculated for each wave, based on the question, "Which best describes the rules about smoking in your home?" A smoke-free household was defined as the response, "No one is allowed to smoke anywhere inside your home". Discrepant reporting (mean 6\%) and non-responses (mean 3\%) to the questions were excluded. The multistage stratified sample design of TUS-CPS was accounted for in all estimates obtained. A series of replicate weights provided by NCI were incorporated using balanced repeated replication with Fay's adjustment factor of 0.5 to adjust final weights. ${ }^{29}$

\section{Percentages of children covered by PCV7}

Starting in 2000, the American Academy of Pediatrics Committee on Infectious Diseases and the Centers for Disease Control and Prevention Advisory Committee on Immunization Practices recommended that all children aged $\leq 23$ months be administered a four-dose series of the 7 -valent pneumococcal conjugate vaccine (PCV7). ${ }^{30} 31$ The percentage of children covered by this vaccine was obtained from the child immunisation files of the National Health Interview Survey (NHIS), ${ }^{32}$ a nationally representative cross-sectional household interview survey administered by the National Center for Health Statistics. Annual percentages of children aged 6 years or less receiving three or more dosages of the vaccine were calculated from 2000, its year of introduction, through 2003, accounting for the complex survey design and weights. An extrapolation of estimated vaccine coverage was made based on the linear trend calculated from the National Immunization Survey (NIS), which is an annual survey of children's immunisation providers representative of children aged 19-35 months, ${ }^{32}$ and applied to the years subsequent to 2003, when NHIS last collected this information.

\section{Paediatric encounters for OM}

National annual paediatric ambulatory visits and hospital discharges for OM were computed for children aged 6 years or less, for whom incidence of OM is highest. ${ }^{20}{ }^{33} \mathrm{OM}$ encounters were defined as primary diagnoses inclusive of visits for both acute and persistent cases identified by International Classification of Diseases, 9th Revision Clinical Modification Codes (ICD-9 CM): 381.00-381.49 and 382.00-382.99.
Data elements primary diagnosis, date of visit and age were obtained from three national surveys covering clinical encounters administered annually by the National Center for Health Statistics. Annual physician office visits for OM were obtained from the National Ambulatory Medical Care Survey (NAMCS). ${ }^{34}$ Annual emergency department visits and hospital outpatient visits for $\mathrm{OM}$ were obtained from the two corresponding files of the National Hospital Ambulatory Medical Care Survey (NHAMCS).$^{35}$ Annual hospital discharges for OM were obtained from the National Hospital Discharge Survey (NHDS). ${ }^{36}$ Survey weights and adjustment for the multistage probability sample designs were used to generate national estimates of annual physician office visits, emergency department visits and hospital outpatient visits with OM primary diagnosis per 1000 children from 1993 through 2006. Total annual ambulatory care visit rates were computed as the sum of these three rates to optimise estimate reliability. Survey weights and adjustment for the multistage probability sample designs were also used to generate national estimates of annual hospital discharges per 100000 children with OM primary diagnosis from 1993 through 2006. US Census Bureau data corresponding to children aged 6 years or less were used for population denominators. ${ }^{37}$

\section{Statistical analysis}

Stata 10.0 SE was used for calculation of percentage of smoke-free households, percentage of children covered by PCV7 and annual ambulatory care visit and hospital discharge rates for $\mathrm{OM}^{38}$ Regression models were calculated using SAS 9.1. ${ }^{39}$ Annual predicted rates of paediatric ambulatory visits and hospital discharges for $\mathrm{OM}$ were computed from linear regression models, adjusted for percentage of smoke-free households with children and percentage of children covered by PCV7 vaccine.

Joinpoint regression analysis using the NCI's SEER Stat 3.4.3 version software was used to investigate statistically significant trends in annual covariate-adjusted rates of paediatric encounters for $\mathrm{OM}$ and to test for statistically significant changes in the temporal pattern of these rates. ${ }^{40}$ Joinpoint finds the best-fitting line for data that span a range of years based on an algorithm that tests whether a multi-segmented line is a significantly better fit then a single or less segmented line. The procedure fits a series of joined straight lines on a logarithmic scale to the trends in the annual covariate-adjusted rates. "Joinpoints" represent the joining of segments at points at which statistically significant $(p \leq 0.05)$ changes in trend are identified among the best fitting lines for each segment. A minimum of zero and maximum of three joinpoints are tested for statistical significance. The estimated annual percentage change (APC) was computed for each established line segment and tested for a statistically significant trend (with a two-sided $p$ value $\leq 0.05$ ).

Average annual percentage change (AAPC), a summary measure of the trend over a pre-specified fixed interval, was also computed, providing a single estimate describing the average APCs over multiple years. AAPC over a fixed interval is the weighted average of the slope coefficients of the underlying joinpoint regression line with the weights equal to the length of each segment over the interval. AAPCs were computed to facilitate comparisons of changes in ambulatory visits and hospital discharges rates over the entire study period.

\section{RESULTS}

\section{Smoke-free households and PCV7 coverage}

The percentage of smoke-free households among those with at least one child aged 6 years or less increased $89 \%$ from $45.5 \%$ in 1993 to $86.1 \%$ in 2006 (figure 1). PCV7 vaccine coverage among 
children aged 6 years or less based on NHIS Child Immunization File data was $0.91 \%$ in 2000 and increased to $46.4 \%$ in 2003 . Extrapolating from the observed trend in NIS reported vaccination rates, coverage increased to $66.2 \%$ in 2006 (figure 1).

\section{Paediatric encounters for $\mathrm{OM}$ and temporal trends}

Total paediatric ambulatory visits with primary diagnosis OM among children aged 6 years or less decreased from 17499517 encounters in 1993 to 10934753 in 2006 . Ambulatory visit rates for $\mathrm{OM}$ decreased $40 \%$ during this time period from 641.5 to 384.4 visits per 1000 children (figure 2). Total paediatric hospital discharges with primary diagnosis OM among children aged 6 years or less decreased from 35832 in 1993 to 10050 in 2006. Hospital discharge rates for $\mathrm{OM}$ decreased $73 \%$ during this time period from 131.4 to 35.3 per 100000 children (figure 2).

The adjusted $R^{2}$ value for the multiple linear regression model of OM ambulatory visit rates adjusted for smoke-free household and PCV7 coverage was 0.76. Adjusted ambulatory visit rates decreased from 1993 to 2006 on the average by $4.6 \%(95 \% \mathrm{CI}$ $4.5 \%$ to $4.8 \%$ ) per year (figure 1 ). The joinpoint model of covariate-adjusted ambulatory visits rates for OM displayed three distinct slopes having inflexion points at years 1998 and 2002. The individual slopes were statistically significant with progressively increasing APCs for the time periods 1993-1998, 1998-2002 and 2002-2006 (table 1). The adjusted $R^{2}$ value for the linear regression model of $\mathrm{OM}$ ambulatory visit rates adjusted for smoke-free households prior to 2001 was 0.68 .

The adjusted $R^{2}$ value for the multiple linear regression model of OM hospital discharge rates adjusted for smoke-free household and PCV7 coverage was 0.96. The joinpoint model of covariate-adjusted hospital discharge rates for OM displayed a single slope. The covariate-adjusted hospital discharge rates for OM decreased more than twice as steeply as ambulatory visits from 1993 to 2006 on the average by $9.8 \%$ per year $(95 \%$ CI $9.1 \%$ to $10.6 \%$ ) (figure 2 ; table 1 ). The adjusted $\mathrm{R}^{2}$ value for the linear regression model of OM hospital discharges adjusted for smokefree households prior to 2001 was 0.89 .

\section{DISCUSSION}

This research demonstrates that the previous increasing trends in paediatric encounters for OM in the USA have reversed since previously reported trends through the mid-1990s and declined through 2006. Average annual rates of decline in paediatric encounters for $\mathrm{OM}$ were $4.6 \%$ and $9.8 \%$ in ambulatory and inpatient hospital settings, respectively. The decreasing trend of paediatric $\mathrm{OM}$ encounters may be attributable to the increasing trend in smoke-free households with children as SHS exposure is an important risk factor for $\mathrm{OM}$ as well as other paediatric diseases. Other possible reasons for this decrease in $\mathrm{OM}$

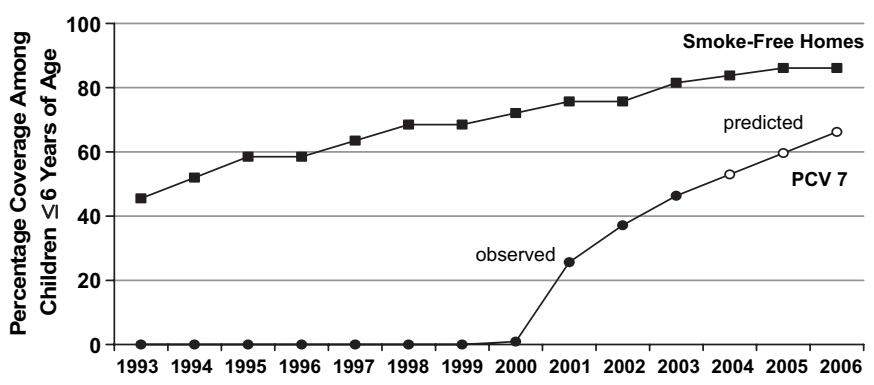

Figure 1 Children living in smoke-free homes and coverage by pneumococcal vaccination (PCV7) 1993-2006.

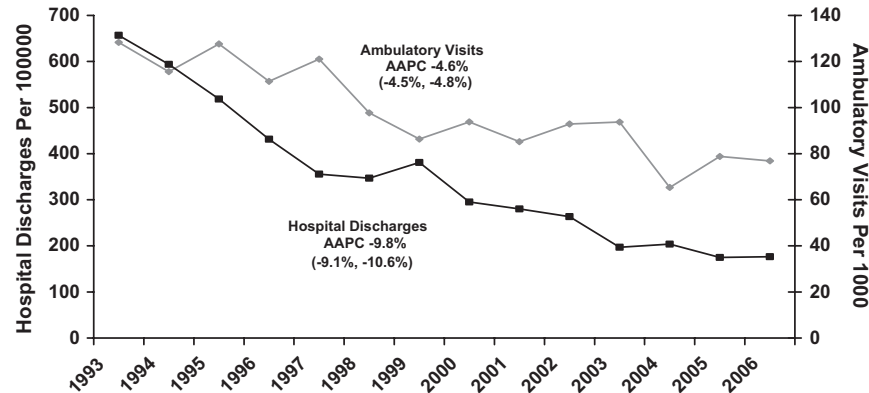

Figure 2 Trends in otitis media encounters.

encounters include an increase in coverage of young children by PCV7 vaccination. The joinpoint analysis marked an accelerated decline of $\mathrm{OM}$ paediatric encounters in the ambulatory care setting from 2002 to 2006 which suggests a possible role of the vaccine. However, the observed decline in ambulatory $O M$ visits began 1993, which was seven years before the vaccine was introduced and general population protection by PCV7 against Streptococcus pneumoniae is unlikely to have occurred until its broader acceptance, two years later in $2002 .{ }^{41}$ PCV7 also is not protective against all three bacterial pathogens that have been isolated from the middle ear fluid of children with OM. ${ }^{42-45}$ The monotonic decreasing trend in paediatric hospital discharge rates for $\mathrm{OM}$ and lack of joinpoints over the study period suggests little or no effect of PCV7 as a time-varying exposure variable on this temporal trend.

Most other risk factors (eg, childcare, health insurance coverage, poverty) had little variation during this period. Annual percentages of 3-5-year old children in centre-based childcare arrangements showed relatively little variability, the lowest at $52.8 \%$ in 1995 and the highest at $59.7 \%$ in $1999 .{ }^{46}$ Annual percentages of children with any health insurance were relatively steady averaging 88\% from 1995 to $2006 .{ }^{47}$ Annual percentages of children living below $100 \%$ poverty level declined slightly from $20 \%$ to $17 \%$ in $2006 .{ }^{47}$

The $40 \%$ decline in annual rates of ambulatory visits for OM found in this study are consistent with reports in the literature of a 33\% decrease between 1995-1996 and 2005-2006 among children under five years of age, ${ }^{48}$ and a $43 \%$ decrease from 1997-1999 to 2004 among privately insured children under two years of age. ${ }^{2}$ In comparison with previously increased office visit rates for $\mathrm{OM}$ per 100 children under age 15 years from 13.1 in 1975 to 36.0 in $1990,{ }^{4}$ the present analyses found decreasing physician office visit rates for $\mathrm{OM}$ among the children under age 15 years from 28.9 per 100 in 1995 to 16.8 per 100 in 2006, now the lowest they have been in three decades. As of 2007, the total medical expenditures for OM among children ages 6 years and less were $\$ 2.0$ billion, ${ }^{49}$ approximately half the amount of previously reported expenditures in the mid-1990s. ${ }^{4-7}$

The ecological study design does not allow direct estimates of the paediatric encounter rates in homes with and without smokers and the results generated cannot be used to infer causation. Since the calculated rates are based on all paediatric encounters, the extent to which the observed decreases may represent reduction of initial and/or repeat visits also could not be determined. Treatment of mild cases elsewhere or with nonprescription medications could result in underestimation of $\mathrm{OM}$ incidence. Some unadjusted confounding may remain if, for example, healthcare utilisation was affected by other factors, such as more watchful waiting physician advice given by phone in order to prevent to over-utilisation of antibiotics. ${ }^{50}$ However, 
Table 1 Joinpoint models of covariate-adjusted annual ambulatory visit and hospital discharge rates

\begin{tabular}{lllll}
\hline $\begin{array}{l}\text { Clinical paediatric } \\
\text { encounter type }\end{array}$ & $\begin{array}{l}\text { Annual percentage change } \\
\text { (APC) or average annual } \\
\text { percentage change (AAPC) }\end{array}$ & Time period & Rate of change (95\% Cl) & Adjusted $\mathbf{R}^{\mathbf{2}}$ \\
\hline Ambulatory visits & APC & $1993-1998$ & $-3.6(-3.7$ to -3.5$)$ & \\
& APC & $1998-2002$ & $-4.6(-4.6$ to -4.0$)$ & \\
& APC & $2002-2006$ & $-5.2(-5.4$ to -5.1$)$ & \\
Hospital discharges & AAPC & $1993-2006$ & $-4.6(-4.8$ to -4.5$)$ & 0.76 \\
& APC & $1993-2006$ & $-9.8(-10.6$ to -9.0$)$ & \\
& AAPC & $1993-2006$ & $-9.8(-10.5$ to -9.1$)$ & 0.96 \\
\hline
\end{tabular}

응

this possibility seems unlikely in light of evidence that prescribing of antibiotics for OM in children increased from 1998 to $2004 .^{51-53}$ The use of self-report data with respect to smokefree households has been questioned, but has the offsetting advantage as a measure of exposure over time with greater sensitivity than nicotine biomarkers with short half-lives. ${ }^{54}$ Smoke-free households may be underestimated if smoking were limited to rare occasional visitors in households reported without no-smoking rules.

Children might on the other hand be exposed to significant SHS outside the home-for example, from grandparents or caregivers. In addition, parents may have recently adopted no-smoking rules following previous older children with OM. Finally, while increases in smoke-free households have been observed across demographic groups, racial and ethnic populations of interest are not represented in the healthcare data in sufficient number for separate estimates. ${ }^{10}$

An ecological study design is, on the other hand, a valid method for estimating public health benefit where measurement, analysis and interpretation are at the group level and an individual level association is evident, ${ }^{55}$ as is the case with regard to the relation between SHS exposure and paediatric OM. Another feature of the present study design is its examination of both paediatric ambulatory visit and hospital discharge rates for children at the ages most susceptible to OM. ${ }^{33}$ The clinical encounter rates were derived from nationally representative survey data that have been reviewed and validated to provide reasonably accurate estimates.

\section{What this paper adds}

Dramatic increases were previously reported in the number of clinical visits for otitis media among children, the most common paediatric diagnosis made in physician office practices and the leading cause of medical encounters among children and preschool-aged children in the USA. The possible role of exposure to secondhand tobacco smoke in the observed trends was not previously considered; and prospective improvements in child health resulting from increases in smoke-free rules among homes with children since the mid-1990s have yet to be assessed. The present research demonstrates that the previous increasing trends in paediatric encounters for otitis media in physician office, hospital ambulatory care and inpatient settings in the USA reversed since previously reported trends in the mid1990s and declined through 2006. The observed steadily increasing trend in smoke-free households since the mid-1990s appears to be the main explanatory factor whose influence cannot be excluded over this entire time period.

\section{CONCLUSIONS}

This is the first study to quantify average annual decreases in paediatric encounters for OM over the past decade and a half. The observed steadily increasing trend in smoke-free households since the mid-1990s is the main explanatory factor whose influence cannot be excluded over this entire time period. The importance of smoke-free rules in homes to protect children from exposure to SHS has further significance, given the range of adverse effects that SHS exposure has on child health. ${ }^{11} 53$ Public health law researchers recently recommended the use of federal regulatory or contractual mechanisms to ensure that public housing authorities implement no-smoking policies for the protection of children and others, ${ }^{56}$ following strong encouragement of such policies expressed in a July 2010 memorandum by the US Department of Housing and Urban Development. ${ }^{57}$ While cardiovascular and other health benefits to the general population resulting from smoke-free indoor air policies in public places are known, ${ }^{58}$ the public health benefits to children from recent advances in smoke-free home policies have not previously been assessed. Further research could help elucidate relations between SHS exposure and paediatric outcomes across demographic groups and analyse trends in paediatric encounters for these as well as other SHS-related diseases.

Acknowledgements The authors thank Dr Kathleen Bennett for statistical advice and Dr Melanie Dove for helpful comments.

Funding Research support for this study is provided by the Flight Attendant Medical Research Institute, Clinical Innovator Award 072085.

Competing interests None.

Contributors All authors contributed to one or more of conception and design, acquisition of data or analysis and interpretation of data in the study, drafting and revising the article, and providing important intellectual content.

Provenance and peer review Not commissioned; externally peer reviewed.

\section{REFERENCES}

1. Ezzati T. Ambulatory Medical Care Rendered in Pediatricians' Offices During 1975. Monthly Vital Statistics Report; 77-1250. Hyattsville, Maryland: National Center for Health Statistics, 1977.

2. Zhou F, Shefer A, Kong Y, et al. Trends in otitis media-related health care utilization by privately insured young children in the United States, 1997-2004. Pediatrics 2008;121:253-60.

3. Casselbrant ML, Mandel EM. Epidemiology. In: Bluestone CD, Rosenfeld RM, eds Evidence-Based Otitis Media. Hamilton, Ontario: BC Decker, 2003:147-62.

4. Schappert SM. Office visits for otitis media: United States, 1975-90. Adv Data 1992;214:1-19.

5. Berman S. Otitis media in children. N Engl J Med 1995;332:1560-5.

6. Gates GA. Cost-effectiveness considerations in otitis media treatment. Otolaryngol Head Neck Surg 1996;114:525-30.

7. Bondy J, Berman S, Glazner J, et al. Direct expenditures related to otitis media diagnoses: extrapolations from a pediatric medicaid cohort. Pediatrics 2000;105:E72.

8. Auinger $\mathbf{P}$, Lanphear BP, Kalkwarf $\mathrm{HJ}$, et al. Trends in otitis media among children in the United States. Pediatrics 2003;112:514-20.

9. Centers for Disease Control and Prevention. Disparities in secondhand smoke exposure-United States, 1988-1994 and 1999-2004. MMWR Morb Mortal Wkly Rep 2008;57:744-7. 
10. Soliman S, Pollack HA, Warner KE. Decrease in the prevalence of environmental tobacco smoke exposure in the home during the 1990s in families with children. Am J Public Health 2004;94:314-20.

11. US Department of Health and Human Services. The Health Consequences of Involuntary Exposure to Tobacco Smoke: A Report of the Surgeon General. Atlanta, GA: US Department of Health and Human Services, Centers for Disease Control and Prevention, Coordinating Center for Health Promotion, National Center for Chronic Disease Prevention and Health Promotion, Office on Smoking and Health, 2006

12. Guerin MR, Jenkins RA, Tomkins BA. The Chemistry of Environmental Tobacco Smoke: Comparison and Measurement. Chelsea, Ml: Lewis Publishers, 1992.

13. US Environmental Protection Agency. Respiratory Health Effects of Passive Smoking: Lung Cancer and Other Disorders. Washington, DC: US Environmental Protection Agency, 1992.

14. Royal College of Physicians. Passive smoking and children. A report by the Tobacco Advisory Group. London: RCP, 2010.

15. Gergen PJ. Environmental tobacco smoke as a risk factor for respiratory disease in children. Respir Physiol 2001;128:39-46.

16. Levy DT, Romano E, Mumford EA. Recent trends in home and work smoking bans. Tob Control 2004:13:258-63.

17. Bettcher DW, Peruga A, Fishbern B, et al. Exposure to secondhand smoke among students aged 13-15 years-worldwide, 2000-2007. MMWR Morb Mortal Wkly Rep 2007:56:497-500. Atlanta, GA: Centers for Disease Control and Prevention

18. Centers for Disease Control and Prevention. State-specific prevalence of smoke-free home rules-United States, 1992-2003. MMWR Morb Mortal Wkly Rep 2007; 56:501-4

19. Centers for Disease Control and Prevention. State-specific prevalence of current cigarette smoking among adults and secondhand smoke rules and policies in homes and workplaces-United States, 2005. MMWR Morb Mortal Wkly Rep 2006:55:1148-51.

20. Bluestone CD, Klein J0, eds. Otitis Media in Infants and Children 4th edn. Hamilton, Ontario: BC Decker, 2007:73-100.

21. Nuorti JP, Martin SW, Smith PJ, et al. Uptake of pneumococcal conjugate vaccine among children in the 1998-2002 United States birth cohorts. Am J Prev Med 2008:34:46-53.

22. Eskola J, Kilpi T, Palmu A, et al; Finnish Otitis Media Study Group. Efficacy of a pneumococcal conjugate vaccine against acute otitis media. $N$ Engl J Med 2001;344:403-9.

23. US Department of Commerce, Census Bureau. National Cancer Institute and Centers for Disease Control and Prevention Co-sponsored Tobacco Use Supplement to the Current Population Survey (2006-07). http://riskfactor.cancer.gov/studies/tuscps, 2008

24. US Department of Commerce, Census Bureau. National Cancer Institute and Centers for Disease Control and Prevention Co-sponsored Tobacco Use Special Cessation Supplement to the Current Population Survey 2003. http://riskfactor.cancer. gov/studies/tus-cps, 2006

25. US Department of Commerce, Census Bureau. National Cancer Institute and Centers for Disease Control and Prevention Co-sponsored Tobacco Use Supplement to the Current Population Survey (2001-2002). http://riskfactor.cancer.gov/studies/tuscps, 2004

26. US Department of Commerce, Census Bureau. National Cancer Institute Sponsored Tobacco Use Supplement to the Current Population Survey (1998-1999). http://riskfactor.cancer.gov/studies/tus-cps, 2000

27. US Department of Commerce, Census Bureau National Cancer Institute Sponsored Tobacco Use Supplement to the Current Population Survey (1995-1996). 1994-1999. http://riskfactor.cancer.gov/studies/tus-cps.

28. US Department of Commerce, Census Bureau. National Cancer Institute Sponsored Tobacco Use Supplement to the Current Population Survey (1992-1993). 1992-1993. http://riskfactor.cancer.gov/studies/tus-cps.

29. Judkins D. Fay's method for variance estimation. J Off Stat 1990:16:25-45.

30. Anon. American Academy of Pediatrics, Committee on Infectious Diseases. Policy statement: recommendations for the prevention of pneumococcal infections, pneumococcal polysaccharide vaccine, and antibiotic prophylaxis including the use of pneumococcal conjugate vaccine (Prevnar). Pediatrics 2000;106:362-6.

31. Centers for Disease Control and Prevention. Preventing Pneumococcal Disease among Infants and Young Children: Recommendations of the Advisory Committee on Immunization Practices (ACIP). MMWR Recomm Rep 2000;49:1-35.
32. Centers for Disease Control and Prevention. National, state, and local area vaccination coverage among children aged 19-35 months-United States, 2006 MMWR Morb Mortal Wkly Rep 2007;56:880-5.

33. Teele DW, Klein J0, Rosner B. Epidemiology of otitis media during the first seven years of life in children in greater Boston: a prospective, cohort study. J Infect Dis 1989;160:83-94.

34. National Center for Health Statistics. National Ambulatory Medical Care Survey Hyattsville, Maryland: Public Health Service, 2008

35. National Center for Health Statistics. National Hospital Ambulatory Medical Care Survey. Hyattsville, Maryland: Public Health Service, 2008

36. National Center for Health Statistics. National Hospital Discharge Survey. Hyattsville, Maryland: Public Health Service, 2008.

37. US Census Bureau; United States Annual Population Estimates. 1995-2006 generated by llan Behm; using American FactFinder. http://factfinder.census.gov 12 Jun 2009

38. StataCorp. Stata Statistical Software: Release 10. College Station, TX: StataCorp LP 2007.

39. SAS software (version 9.1). Cary, NC: SAS Institute Inc.

40. Joinpoint Regression Program, Version 3.4.3. Statistical Research and Applications Branch, National Cancer Institute, 2010.

41. Grijalva CG, Nuorti JP, Griffin MR. Antibiotic prescription rates for acute respiratory tract infections in US ambulatory settings. JAMA 2009:19:758-66.

42. Bluestone CD, Stephenson JS, Martin LM. Ten-year review of otitis media pathogens. Pediatr Infect Dis J 1992;11(Suppl 8):S7-11.

43. Heikkinen $\mathbf{T}$, Thint $\mathrm{M}$, Chonmaitree $T$. Prevalence of various respiratory viruses in the middle ear during acute otitis media. N Engl J Med 1999:340:260-4.

44. Jacobs MR, Dagan R, Appelbaum PC, et al. Prevalence of antimicrobial-resistant pathogens in middle ear fluid: multinational study of 917 children with acute otitis media. Antimicrob Agents Chemother 1998;42:589-95.

45. Luotonen J, Herva E, Karma P, et al. The bacteriology of acute otitis media in children with special reference to Streptococcus pneumoniae as studied by bacteriological and antigen detection methods. Scand J Infect Dis 1981:13:177-83.

46. US Department of Education, National Center for Education Statistics. National Household Education Surveys Program. http://nces.ed.gov/nhes/dataproducts.asp.

47. Annual Social and Economic Supplements. Washington DC: Current Population Survey, US Department of Labor. Bureau of Labor Statistics, 1995-2006.

48. Grijalva CG, Poehling KA, Nuorti JP, et al. National impact of universal childhood immunization with pneumococcal conjugate vaccine on outpatient medical care visits in the United States. Pediatrics 2006:118:865-73.

49. Medical Expenditures Panel Survey. Household Component Summary Data Tables Rockville, MD: Agency for Healthcare Research and Quality. http://meps.ahrq.gov/ mepsweb/data stats/quick tables search.jsp?component $=1$ \&subcomponent $=0$ (accessed 30 Jun 2010)

50. Dowell SF, Marcy SM, Phillips WR, et al. Principles of judicious use of antimicrobial agents for pediatric upper respiratory tract infections. Pediatrics 1998;101(Suppl):163-5

51. Vernacchio L, Vezina RM, Mitchell AA. Management of acute otitis media by primary care physicians: trends since the release of the 2004 American Academy of Pediatrics/American Academy of Family Physicians clinical practice guideline. Pediatrics 2007:120:281-7.

52. Coco A, Vernacchio L, Horst M, et al. Management of acute otitis media after publication of the 2004 AAP and AAFP clinical practice guideline. Pediatrics 2010:125:214-20.

53. Coco AS, Horst MA, Gambler AS. Trends in broad-spectrum antibiotic prescribing for children with acute otitis media in the United States, 1998-2004. BMC Pediat 2009:9:41.

54. Benowitz NL, Kuyt F, Jacob P III, et al. Cotinine disposition and effects. Clin Pharmacol Ther 1983;309:139-42.

55. Stevenson $\mathbf{M}$, McClure R. Use of ecological study designs for injury prevention. Inj Prev 2005;11:2-4

56. Winickoff JP, Gottlieb M, Mello MM. Regulation of smoking in public housing N Engl J Med 2010;362:2319-25.

57. Department of Housing and Urban Development, Office of Public and Indian Housing. Non-smoking policies in public housing. 17 Jul 2009 (memorandum). http://www.hud.gov/offices/pih/publications/notices/09/pih2990-21.pdf (accessed 27 Jun 2010).

58. Institute of Medicine. Secondhand Smoke Exposure and Cardiovascular Effects: Making Sense of the Evidence. Washington, DC: National Academies Press, 2009. 